\title{
THE ROLE OF SELENOPROTEINS IN CANCER
}

\author{
Kaluce Gonçalves de Sousa Almondes ${ }^{1 *}$, Greisse Viero da Silva Leal², Silvia Maria Franciscato Cozzolino³ ${ }^{3}$, Sonia Tucunduva Philippiª ${ }^{4}$ Patrícia Helen de Carvalho \\ RoNDó 4 \\ Study conducted at School of Public Health, Universidade de São Paulo, São Paulo, SP, Brazil
}

\author{
*Correspondence: \\ Rua Valdemar Ferreira, \\ 359 - Butantã \\ São Paulo, SP, Brazil \\ CEP: 05501-000 \\ Phone/Fax: $(+5511)$ \\ 6720-3261 / 3815-4410
}

\begin{abstract}
Evidence has shown that metabolic disorders are common in tumor cells, leading to increased oxidative stress. The increase in the production of reactive oxygen species (ROS) associated with low antioxidant activity has been related to several types of cancer. Selenium, an antioxidant micronutrient, may function as an antimutagenic agent, preventing the malignant transformation of normal cells. A review of the literature was conducted based on a survey of articles published between 2000 and 2009 in the PubMed database; 39 articles that analyzed the relationship between cancer, oxidative stress and selenium supplementation were selected. The protective effect of this mineral is especially associated with its presence in the glutathione peroxidase and thioredoxin reductase, enzymes that are known to protect DNA and other cellular components against oxidative damage caused by ROS. Several studies have shown reduced expression of these enzymes in various types of cancer, especially when associated with low intake of selenium, which may increase the damage. Selenium supplementation appears to reduce the risk of some types of cancer by reducing oxidative stress and DNA damage. However, further studies are needed to clarify the adequate dose of selenium for each situation (sex, geographic location, and type of cancer).
\end{abstract}

KEY wORDS: Selenium. Selenoproteins. Dietary supplementation. Neoplasms. Oxidative stress.

\section{INTRODUCTION}

Evidence has shown that metabolic disorders are common in tumor cells, leading to increased oxidative stress. According to Cutler, ${ }^{1}$ oxidative stress is defined as an imbalance between antioxidants and reactive oxygen species (ROS) in favor of the latter. ROS, which include free radicals, are continuously produced in the body and play an important physiological role at low concentrations.

At high concentrations, due to their high reactivity, ROS can cause irreversible damage through oxidative changes in lipids, proteins, and DNA. It is suspected that changes in these structures are related to the development of several human diseases, including cancer. ${ }^{1}$

To limit the harmful effects of ROS, a high-performance antioxidant system composed of an enzymatic and a nonenzymatic system may interact with ROS by regulating their production, reducing it to physiological limits. If this antioxidant defense is surpassed by the production of ROS or not sufficiently provided through diet or supplementation, oxidative stress can occur. ${ }^{1}$

Selenium (Se), a micronutrient with an important antioxidant action, functions as an antimutagenic agent, preventing the malignant transformation of normal cells. This protective effect of selenium was primarily associated with its presence in the glutathione peroxidase and thioredoxin reductase, enzymes that are known to protect DNA and other cellular components from oxidative damage. ${ }^{2,3}$

Some mechanisms have been suggested to explain the anticarcinogenic effects of selenium: the action of selenoenzymes in reducing DNA damage, oxidative stress reduction, reduced inflammation, detoxification, improved immune response, increased tumor suppressor protein p53, inactivation of protein kinase $\mathrm{C}$, alteration in DNA methylation, cell cycle arrest, induction of apoptosis of cancer cells, and inhibition of angiogenesis. ${ }^{3-6}$

1. Graduação em Nutrição - mestranda em Nutrição Experimental no departamento de Alimentos e Nutrição Experimental da Faculdade de Ciências Farmacêuticas da Universidade de São Paulo, São Paulo, SP

2. Mestre em Saúde Pública - doutoranda em Nutrição e Saúde Pública no departamento de Nutrição da Faculdade de Saúde Pública da Universidade de São Paulo, São Paulo, SP

3. Livre-Docente em Nutrição - professora titular e chefe do departamento de Alimentos e Nutrição Experimental da Faculdade de Ciências Farmacêuticas da Universidade de São Paulo, São Paulo, SP

4. Livre-Docente em Nutrição - professoras associadas do departamento de Nutrição da Faculdade de Saúde Pública da Universidade de São Paulo, São Paulo, SP 
This study aimed to gather information about the relationship between cancer, oxidative stress and supplementation with selenium. For this purpose, we provided an overview of selenium and the major selenoproteins, their response in the face of certain types of cancer, and issues related to supplementation.

\section{Methods}

A review of the literature was conducted based on a survey of articles published between 2000 and 2009 in the PubMed database, using "selenium" and "cancer" as search descriptors. Our search detected 1263 articles; of these, we selected those written in English, with animals and humans, and that investigated the antioxidant action of selenium and its supplementation in cancer, totaling 39 articles.

\section{Selenoproteins and their actions}

Selenium is a trace element essential for the normal function of the body and can be present in inorganic form, metallic form $\left(\mathrm{Se}^{0}\right)$ or oxyanions, such as selenite $\left(\mathrm{SeO}(\mathrm{OH})_{2}\right)$ and selenate $\left(\mathrm{SeO}_{2}(\mathrm{OH})_{2}\right)$, and also in organic forms, such as selenocysteine (SeCys) and selenomethionine (SeMet), analogs of sulfurcontaining amino acids cysteine and methionine, respectively. ${ }^{7}$

Once selenium compounds are recognized as selenium species, they are transformed into selenide, a common intermediate metabolite, and then used for the synthesis of selenoproteins (selenoenzymes) or excreted after being methylated stepwise. SeMet is an exceptional selenium compound, since, when recognized as a selenium species, it can be transformed into SeCys through the trans-selenation pathway and then lysed by $\beta$-lyase ou y-lyase to selenide. However, at the same time, SeMet can be used for the synthesis of proteins without the body distinguishing between SeMet and methionine, ${ }^{7}$ by methionine-tRNA. ${ }^{8}$

SeCys is present as an amino acid residue in selenoproteins in plants and animals, which is incorporated into amino acid sequences of selenoproteins by a specific codon to SeCys residue. SeMet is present in the form of SeMet residue in general proteins. Thus, proteins containing selenium in the form of SeCys are called selenoproteins, while those containing selenium in the form of SeMet are simply called seleniumcontaining proteins. ${ }^{7}$

Currently, five human glutathione peroxidase (GPx) isoenzymes containing SeCys are known, exhibiting tissue-specific expressions and different substrate specificities. ${ }^{9}$ They are: GPX-1, found in the cytosol; GPx-2, an enzyme specific to the gastrointestinal tract; GPX-3, secreted into plasma proteins; GPX-4, acts on oxidized lipids, being called phospholipid hydroperoxide GPx; and snGPx, a specific sperm nuclei enzyme. ${ }^{10}$ All these GPx isoenzymes have in common a catalytic triad within their active center, consisting of SeCys, glutamine, and tryptophan residues. ${ }^{11}$ Their antioxidant capacity is due to a reduction in hydrogen peroxidase, organic hydroperoxide and phospholipid hydroperoxide (only GPx-4), usually requiring two glutathione equivalents as a cosubstrate. ${ }^{12}$

In addition to GPx, the thioredoxin reductase ( $\operatorname{Tr} x$ R) selenoenzyme family is also capable of degrading hydroperoxides, as demonstrated by the reduction in hydrogen peroxide and lipid hydroperoxide by human placenta $\operatorname{TrxR} .{ }^{13} \operatorname{TrxR}$ catalyzes the reduction of thioredoxin primarily, but in humans it can also reduce other substrates, such as vitamin $\mathrm{C}$. Thioredoxin catalyzes the reduction of protein disulfides and is involved in numerous vital processes, such as DNA synthesis and regulation of apoptosis. ${ }^{14}$ All three human TrxR isoenzymes contain an essential SeCys residue in their C-terminal: cytosolic TrxR-1; mitochondrial TrxR-2; and TrxR-3, a testis-specific glutathione/ thioredoxin reductase. ${ }^{15,16}$

Regardless of the direct reduction of hydroperoxides, TrxRs are involved in the protection against ROS by controlling the redox state of thioredoxin. ${ }^{17}$ Therefore, reduced thioredoxin may serve as an electron donor for numerous intra and extracellular antioxidant enzymes: thioredoxin reduces several oxidized peroxiredoxins, a large family of cytoprotective enzymes that degrade hydroperoxide and peroxynitrite, thereby restoring their enzymatic activity. ${ }^{18}$ Methionine sulfoxide reductase, which repairs oxidized methionine residues in proteins, ${ }^{19}$ requires thioredoxin for its subsequent reduction ${ }^{20}$.

In the extracellular environment, where glutathione levels are usually low compared to the intracellular compartment, ${ }^{21}$ thioredoxin can replace glutathione as an electron donor for redox reactions. ${ }^{10}$ Plasma GPx (GPx-3), the most important selenoenzyme in the detoxification of ROS in human plasma, catalyzes the reduction of extracellular hydrogen peroxide and lipid hydroperoxide and accepts both thioredoxin and glutathione as a reduction cosubstrate. ${ }^{22}$

Selenoprotein $\mathrm{P}(\mathrm{SeP})$, the second selenoprotein to be discovered, was designated " $P$ " for being found in blood plasma. Incomplete isoforms of this protein have been found and may contain from 1 to 17 SeCys, depending on the animal species. $\mathrm{SeP}$ is expressed in many tissues, but it is produced primarily in the liver and secreted into the plasma. SeP is the largest form of selenium in plasma and is involved in its transport. ${ }^{23,24}$ There are indications that $\mathrm{SeP}$ also acts as an antioxidant in the extracellular space. SeP is located in the endothelium, bound to heparin and associated with carbohydrates. ${ }^{24}$ SeP can reduce peroxynitrite and phospholipid hydroperoxide, ${ }^{25,26}$ can form mercury- and cadmium-selenium complexes, ${ }^{27}$ and can also stimulate the survival of cultured central neurons. ${ }^{28}$

There is experimental evidence for an additional role of SeP as a ROS detoxification enzyme. Two enzymatic activities of SeP were demonstrated in vitro: SeP reduced phospholipid hydroperoxides using glutathione or thioredoxin as a cosubstrate ${ }^{26,29}$ and protected plasma proteins against oxidation and nitration induced by peroxynitrite or peroxidation of low density lipoproteins (LDL). ${ }^{25,30}$ In addition, SeP was also shown to protect human astrocytes and endothelial cells from oxidative damage. ${ }^{31,32}$

\section{Selenoproteins and cancer prevention}

Since the genotoxic damage caused by the accumulation of oxidative modifications in DNA bases and DNA single- or double-strand breaks are outstanding features in the development of many forms of cancer, selenium has been suggested to exert its anticarcinogenic function through ROS detoxification selenoenzymes. In humans, indirect evidence for the 
connection between cancer risk and a pattern of altered expression of selenoproteins has been provided by genetic data such as proliferation of cancer tissue expressions. ${ }^{9}$

An allelic variant of GPx-1 gene, with high prevalence among Caucasians caused by a single nucleotide polymorphism at codon 198, was associated with increased risk of lung cancer. ${ }^{33}$ In addition, loss of one GPx-1 allele (loss of heterozygosity) is frequently observed in DNA from tissues with lung cancer. ${ }^{34} \mathrm{~A}$ significant reduction in the regulation of SeP mRNA levels was found in colorectal and prostate cancer tissues. ${ }^{35,36}$ DDuring the progression of colorectal cancer, GPx-1, GPx-3 and SeP expressions decrease, whereas GPx-2 expression increases. ${ }^{37}$ TrxR-1 overexpression is also characteristic of several forms of cancer. ${ }^{38}$

Studies in animals and cell cultures have corroborated the anticarcinogenic role of several selenoenzymes. Accelerated carcinogenesis of the prostate was observed in transgenic mice displaying impaired selenoprotein biosynthesis, ${ }^{39}$ and selenium status was shown to be inversely correlated with the extent of DNA damage in the prostate of elderly beagle dogs. ${ }^{40}$ GPX-1 overexpression as well as selenium supplementation protected mammalian cells against ultraviolet (UV)-induced DNA damage. ${ }^{41}$ GPx-4 overexpression impeded solid tumor growth of tumorigenic L929 fibrosarcoma cells and increased the sensitivity of tumorigenic B16BL6 melanoma cells to angiodestructive therapy. ${ }^{42}$

The anticarcinogenic role of GPx-1, GPx-4 and SeP appears to rely mostly on their function as hydroperoxide degradation enzymes. In contrast, GPx-2 and TrxR-1 certainly act as a "double-edged sword" exhibiting anti and procarcinogenic properties. This dual role of GPx-2 has been recently highlighted by an approach using small interfering RNA (siRNA) to knock down GPx-2 expression, which inhibited migration and invasion of human adenocarcinoma cells, but supported tumor cell growth in mice. ${ }^{43}$

The same experimental approach was used before to evaluate the role of TrxR-1 in carcinogenesis: siRNA-induced TrxR-1 knockdown in mouse lung carcinoma cells caused a reversal in tumor phenotype and inhibition of tumor growth and metastasis. ${ }^{44}$ On the other hand, TrxR-1 assists in cancer prevention by degrading hydroperoxides, ${ }^{13}$ supplying reduced thioredoxin to the reduction of oxidized peroxiredoxins, ${ }^{18}$ and controlling the redox state of many transcription factors. ${ }^{45,46}$

Other selenocompounds affect the signal transduction in tumor cells, as demonstrated by methylseleninic acid (MSeA). In fibrosarcoma cells, MSeA inhibited the activation of matrix metalloproteinase-2 (MMP-2) by promoting 12-0-tetradecanoylphorbol-13-acetate (PMA) in the tumor through the suppression of nuclear factor-kappa B (NF-KB) signal pathway. ${ }^{47}$ Protein kinase $C$ (PKC), which is activated by PMA and involved in carcinogenesis, was shown to be inactivated by locally generated MSeA. ${ }^{48}$

$\mathrm{PKC}$ reduction is bound to lipid hydroperoxides by the MSeA-generated selenocompound methylselenol, which inactivates PKC through the specific oxidation of sulfhydryls in its catalytic domain. The redox modification of PKC can be reversed by TrxR-1 using thioredoxin as a reduction cosubstrate. This sophisticated model can explain the interrelationship between the actions of selenocompounds and TrxR-1 selenoenzyme in controlling PKC activity, and may eventually contribute to a better understanding of the complex anti- and pro-oxidative effect of selenium in cancer prevention. ${ }^{48}$

\section{Selenium supplementation as a chemopreventive agent}

Selenium is an essential nutrient with anticarcinogenic potential, particularly when supplemented. The main forms of selenium supplement are SeMet and SeCys. In low doses, selenium functions as an essential component of SeCys in various specific selenoproteins and promotes cell proliferation, important for immune response. In high but nontoxic doses, selenium may reduce the risk of cancer by blocking tumor cell cycle, stimulating apoptosis, and inhibiting tumor cell migration and invasion. ${ }^{49}$

In a review conducted by Navarro-Alcarón et al., ${ }^{50}$ fthe authors found 14 studies showing significantly low selenium levels in cancer patients compared to controls. Low serum selenium concentration was also correlated with increased risk of cancer. In addition, Czeczot et al. ${ }^{51}$ found a reduction in GPx activity in hepatocellular carcinoma compared to adjacent normal tissue. This reduction may cause the intensification of lipid peroxidation and the increased level of final products of peroxidation, such as malondialdehyde (MDA). Concomitantly, increased levels of MDA in cancer tissues were also found. Therefore, some researchers recommend selenium in nutritional cancer prophylaxis at doses of 50 to $100 \mu \mathrm{g}$ Se/day. Selenium has also been recommended as an adjuvant to chemotherapy in the treatment of cancer at doses of $200 \mu \mathrm{g} \mathrm{Se/day.}{ }^{52,53}$

The first double-blind study using selenium as a chemopreventive agent, Nutritional Prevention of Cancer (NPC), was published in 1996 by Clark et al. ${ }^{54}$ A total of 1312 individuals of both sexes were studied and no significant effects were observed in the incidence of nonmelanoma skin cancer after daily supplementation with $200 \mu \mathrm{g}$ Se/day. Using data from this same study, 457 men who received such selenium supplementation were compared to 470 men receiving placebo (a seven-year follow-up study), and a significantly lower incidence of prostate, lung and colorectal cancer was observed among those supplemented. ${ }^{55,56}$

More recent data on cancer-related selenium supplementation have been observed. In a randomized double-blind study with individuals at high risk of developing prostate cancer, patients received selenium supplementation for six months. After this period, TrxR activity of the group increased by $80 \%$. However, GPx activity was not affected. ${ }^{57}$

Observing the effect of selenium supplementation on GPX expression in different lung cancer cell lines (H460, H1703, H1944), Romanowska et al.58 found that the full expression of GPx-1 and GPx-4 in these cells requires the presence of at least $100 \mathrm{nM}$ of selenium. The impact of selenium supplementation varied according to the type of lung cancer cell and the type of GPx. In two cancer cell lines, selenium deficiency reduced GPX-1 levels, but had no effect on GPx-4. In a third cell line, GPX-1 showed minimal expression regardless of selenium concentration, but GPx-4 was highly responsive to supplementation.

Studies in animals have shown a protective effect of various 
forms of selenium against many types of cancer, including liver, skin, mammary, and colon cancer. In particular, the development of 7,12-dimethybenzanthracene (DMBA)-induced mammary cancer and UV-induced skin cancer was significantly reduced in animals receiving selenium. ${ }^{59,60}$. In a rat model, selenium supplementation also significantly reduced the carcinogenic process in chemically induced liver cancer when administered during the promotion and progression phases. ${ }^{61}$

In a review conducted by Bardia et al., ${ }^{62}$ the authors concluded that selenium supplementation appears to reduce the risk of cancer, especially among men, but the results should be interpreted with caution due to variations in selenium concentrations according to sex and geographic location. Men showed higher serum selenium levels than women after supplementation, and most studies were conducted in areas where individuals were likely to be nutritionally deficient in selenium.

A larger number of epidemiological studies using interventional selenium supplementation in the treatment of cancer might provide further data to better define the benefits and risks of different types and doses of selenium to be used. ${ }^{14}$

Moreover, studies evaluating the importance of selenium in cancer treatment in humans refer more to the role of this mineral in prostate and colorectal cancer ${ }^{63-69}$ and less to its role in cases of bladder cancer. ${ }^{70,71}$

\section{CONCLUSION}

Low selenium concentrations, as well as a reduced expression of selenoproteins, are associated with a high risk of cancer.

Studies in animals and humans have shown that selenium has a protective effect in the prevention and treatment of cancer, highlighting that supplementation with this mineral has yielded good results in reducing the carcinogenic process. However, further studies are necessary to elucidate the effect of selenoproteins on various types of cancer, focusing not only on prostate and colorectal tumors, which are the most cited in the literature. Furthermore, the adequate dose of selenium for each situation (sex, geographic location, and type of cancer) should be investigated.

Conflict of interest: No conflicts of interest declared concerning the publication of this article

\section{ACKNOWLEDGEMENTS}

We would like to thank Fundação de Amparo à Pesquisa do Estado de São Paulo (FAPESP) for the financial support.

\section{References}

1. Cutler RG. Oxidative stress profiling: part I. Its potential importance in the optimization of human health. Ann N Y Acad Sci. 2005;1055:93-135.

2. Trueba GP, Sanchez GM, Giuliani A. Oxygen free radical and antioxidant defense mechanism in cancer. Front Biosci. 2004;9:2029-44

3. Schrauzer GN. Anticarcinogenic effects of selenium. Cell Mol Life Sci. 2000;57:1864-73.

4. Rayman MP. Selenium in cancer prevention: a review of the evidence and mechanism of action. Proc Nutr Soc. 2005;64:527-42.

5. Naithani R. Organoselenium compounds in cancer chemoprevention. Mini Rev Med Chem. 2008;8:657-68.

6. Kim YS, Milner J. Molecular targets for selenium in cancer prevention. Nutr Cancer. 2001;40:50-4

7. Suzuki KT. Metabolomics of selenium: Se metabolites based on speciation studies. J Sci. 2005;51:107-44.
8. Schrauzer GN. Selenomethionine: a review of its nutritional significance, metabolism and toxicity. J Nutr. 2000;130:1653-6.

9. Steinbrenner $\mathrm{H}$, Sies $\mathrm{H}$. Protection against reactive oxygen species by selenoproteins. Biochim Biophys Acta. 2009;1790:1478-85.

10. Ottaviano FG, Handy DE, Loscalzo J. Redox regulation in the extracellular environment. Circ J. 2008;72:1-16.

11. Maiorino M, Aumann KD, Brigelius-Flohé R, Doria D, Van den Heuvel J, McCarthy J, et al. Probing the presumed catalytic triad of selenium-containing peroxidases by mutational analysis of phospholipid hydroperoxide glutathione peroxidase (PHGPX). Biol Chem Hoppe Seyler. 1995;376:651-60.

12. Brigelius-Flohé R. Tissue-specific functions of individual glutathione peroxidases. Free Radic Biol Med. 1999;27:951-65.

13. Björnstedt M, Hamberg M, Kumar S, Xue J, Holmgren A. Human thioredoxin reductase directly reduces lipid hydroperoxides by NADPH and selenocystine strongly stimulates the reaction via catalytically generated selenols. J Biol Chem. 1995;270:11761-4.

14. Gromadzinska J, Reszka E, Bruzelius K, Wasowicz W, Akesson B. Selenium and cancer: biomarkers of selenium status and molecular action of selenium supplements. Eur J Nutr. 2008;47 (Suppl 2):29-50.

15. Papp LV, Lu J, Holmgren A, Khanna KK. From selenium to selenoproteins: synthesis, identity, and their role in human health. Antioxid Redox Signal. 2007;9:775-806.

16. Gladyshev VN, Jeang KT, Stadtman TC. Selenocysteine, identified as the penultimate $\mathrm{C}$-terminal residue in human $\mathrm{T}$-cell thioredoxin reductase, corresponds to TGA in the human placental gene. Proc Natl Acad Sci USA. 1996;93:6146-51.

17. Rubartelli A, Bajetto A, Allavena G, Wollman E, Sitia R. Secretion of thioredoxin by normal and neoplastic cells through a leaderless secretory pathway. J Biol Chem. 1992;267:24161-4.

18. Rhee SG, Chae HZ, Kim K. Peroxiredoxins: a historical overview and speculative preview of novel mechanisms and emerging concepts in cell signaling. Free Radic Biol Med. 2005;38:1543-52.

19. Moskovitz J, Singh VK, Requena J, Wilkinson BJ, Jayaswal RK, Stadtman ER. Purification and characterization ofmethionine sulfoxide reductases from mouse and Staphylococcus aureus and their substrate stereospecificity. Biochem Biophys Res Commun. 2002;290:62-5.

20. Arnér ES, Holmgren, A. Physiological functions of thioredoxin and thioredoxin reductase. Eur J Biochem. 2000; 267:6102-9

21. Jones DP, Carlson JL, Mody VC, Cai J, Lynn MJ, Sternberg P. Redox state of glutathione in human plasma. Free Radic Biol Med. 2000;28:625-35.

22. Björnstedt M, Xue J, Huang W, Akesson B, Holmgren A. The thioredoxin and glutaredoxin systems are efficient electron donors to human plasma glutathione peroxidase. J Biol Chem. 1994:269:29382-4.

23. Akesson B, Bellew T, Burk RF. Purification of selenoprotein P from human plasma. Biochim Biophys Acta. 1994;1204 243-9.

24. Burk RF, Hill KE, Motley AK. Selenoprotein metabolism and function: evidence for more than one function for selenoprotein P. J Nutr. 2003;133(Suppl 1): 1517 S-20S.

25. Arteel GE, Mostert V, Oubrahim H, Briviba K, Abel J, Sies H. Protection by SeP in human plasma against peroxynitrite-mediated oxidation and nitration. J Biol Chem. 1998;379:1201-5

26. Saito Y, Hayashi T, Tanaka A, Watanabe Y, Suzuki M, Saito E, et al. Selenoprotein $P$ in human plasma as an extracellular phospholipid hydroperoxide glutathione peroxidase. Isolation and enzymatic characterization of human selenoprotein P. J Biol Chem. 1999;274:2866-71.

27. Suzuki KT, Sasakura C, Yoneda S. Binding sites for the (Hg-Se) complex on selenoprotein P. Biochem Biophys Acta. 1998;1429:102-12.

28. Yan J, Barrett JN. Purification from bovine serum of a survival-promoting factor for cultured central neurons and its identification as selenoprotein-P. J Neurosci. 1998;18:8682-91.

29. Takebe G, Yarimizu J, Saito Y, Hayashi T, Nakamura H, Yodoi J, et al. A comparative study on the hydroperoxide and thiol specificity of the glutathione peroxidase family and selenoprotein P. J Biol Chem. 2002;277:41254-8.

30. Traulsen H, Steinbrenner H, Buchczyk DP, Klotz LO, Sies H, Selenoprotein $P$ protects low-density lipoprotein against oxidation. Free Radic Res. 2004;38:123-8

31. Steinbrenner H, Alili L, Bilgic E, Sies H, Brenneisen P. Involvement of selenoprotein $P$ in protection of human astrocytes from oxidative damage. Free Radic Biol Med. 2006; 40:1513-23.

32. Steinbrenner $H$, Bilgic $E$, Alili L, Sies $H$, Brenneisen P. Selenoprotein $P$ protects endothelial cells from oxidative damage by stimulation of glutathione peroxidase expression and activity. Free Radic Res. 2006;40:936-43.

33. Ratnasinghe D, Tangrea JA, Andersen MR, Barrett MJ, Virtamo J, Taylor PR, et al. Glutathione peroxidase codon 198 polymorphism variant increases lung cancer risk. Cancer Res. 2000;60:6381-3.

34. Moscow JA, Schmidt L, Ingram DT, Gnarra J, Johnson B, Cowan KH. Loss of heterozygosity of the human cytosolic glutathione peroxidase I gene in lung cancer. Carcinogenesis. 1994;15:2769-73.

35. Al-Taie OH, Uceyler N, Eubner U, Jakob F, Mörk H, Scheurlen M, et al. Expression profiling and genetic alterations of the selenoproteins GI-GPx and SePP in colorectal carcinogenesis. Nutr Cancer. 2004;48:6-14. 
36. Calvo A, Xiao N, Kang J, Best CJ, Leiva I, Emmert-Buck MR, et al. Alterations in gene expression profiles during prostate cancer progression: functional correlations to tumorigenicity and down-regulation of selenoprotein-P in mouse and human tumors. Cancer Res. 2002;62:5325-35.

37. Murawaki Y, Tsuchiya H, Kanbe T, Harada K, Yashima K, Nozaka K, et al. Aberrant expression of selenoproteins in the progression of colorectal cancer. Cancer Lett. 2008;259:218-30.

38. Urig S, Becker K. On the potential of thioredoxin reductase inhibitors for cancer therapy. Semin Cancer Biol. 2006;16:452-65.

39. Diwadkar-Navsariwala V, Prins GS, Swanson SM, Birch LA, Ray VH, Hedayat $S$, et al. Selenoprotein deficiency accelerates prostate carcinogenesis in a transgenic model. Proc Natl Acad Sci USA. 2006;23:8179-84.

40. Waters DJ, Shen S, Glickman LT, Cooley DM, Bostwick DG, Qian J, et al. Prostate cancer risk and DNA damage: translational significance of selenium supplementation in a canine model. Carcinogenesis. 2005;26:1256-62.

41. Baliga MS, Wang H, Zhuo P, Schwartz JL, Diamond AM. Selenium and GPX-1 overexpression protect mammalian cells against UV-induced DNA damage. Biol Trace Elem Res. 2007;115:227-42.

42. Heirman I, Ginneberge D, Brigelius-Flohé R, Hendrickx N, Agostinis P, Brouckaert $\mathrm{P}$, et al. Blocking tumor cell eicosanoid synthesis by GPx 4 impedes tumor growth and malignancy. Free Radic Biol Med. 2006;40:285-94

43. Banning A, Kipp A, Schmitmeier S, Löwinger M, Florian S, Krehl S, et al. Glutathione peroxidase 2 inhibits cyclooxygenase-2-mediated migration and invasion of HT-29 adenocarcinoma cells but supports their growth as tumors in nude mice. Cancer Res. 2008;68:9746-53.

44. Yoo MH, Xu XM, Carlson BA, Gladyshev VN, Hatfield DL. Thioredoxin reductase 1 deficiency reverses tumor phenotype and tumorigenicity of lung carcinoma cells. J. Biol Chem. 2006;281:13005-8.

45. Lillig, $\mathrm{CH}$, Holmgren, A. Thioredoxin and related molecules--from biology to health and disease. Antioxid Redox Signal. 2007;9:25-47.

46. Cassidy PB, Edes K, Nelson CC, Parsawar K, Fitzpatrick FA, Moos $\mathrm{PJ}$.Thioredoxin reductase is required for the inactivation of tumor suppressor p53 and for apoptosis induced by endogenous electrophiles. Carcinogenesis. 2006;27:2538-49.

47. Park JM, Kim A, Oh JH, Chung AS. Methylseleninic acid inhibits PMAstimulated pro-MMP-2 activationmediated byMT1-MMP expression and further tumor invasion through suppression of NF-kappaB activation. Carcinogenesis. 2007:28:837-47.

48. Gundimeda U, Schiffman JE, Chhabra D, Wong J, Wu A, Gopalakrishna R. Locally generated methylseleninic acid induces specific inactivation of protein kinase $C$ isoenzymes: relevance to selenium-induced apoptosis in prostate cancer cells. J Biol Chem. 2008;283:34519-31.

49. Zeng $H$, Combs Jr GF. Selenium as an anticancer nutrient: roles in cell proliferation and tumor cell invasion. J Nutr Biochem. 2008;19:1-7.

50. Navarro-Alcaron M, Cabrera-Vique C. Selenium in food and the human body: A review. Sci Total Environ. 2008;400:115-41.

51. Czeczot H, Scibior D, Skrzycki M, Podsiad M. Glutathione and GSH-dependant enzymes in patients with liver cirrhosis and hepatocellular carcinoma. Acta Biochim Pol. 2006;53:237-41.

52. Simonoff M, Simonoff G, editors. Le selenium. Paris: Masson; 1991

53. Reid ME, Duffield-Lillico AJ, Slate E, Natarajan N, Turnbull B, Jacobs E, et al. The nutritional prevention of cancer: $400 \mathrm{mcg}$ per day selenium treatment. Nutr Cancer. 2008;60:155-63.

54. Clark LC, Combs GF, Turnbull BW, Slate EH, Chalker DK, Chow J, et al. Effects of selenium supplementation for cancer prevention in patients with carcinoma of the skin: a randomized controlled trial: nutritional prevention of cancer study group. JAMA. 1996;276:1957-63.

55. Duffield-Lillico AJ, Reid ME, Turnbull BW, Combs GF Jr, Slate EH, Fischbach $\mathrm{LA}$, et al. Baseline characteristics and the effect of selenium supplementation on cancer incidence in a randomized clinical trial: a summary report of the nutritional prevention of cancer trial. Cancer Epidemiol Biomarkers Prev. 2002;11:630-9

56. Duffield-Lillico AJ, Dalkin BL, Reid ME, Turnbull BW, Slate EH, Jacobs ET, et al. Selenium supplementation, baseline plasma selenium status and incidence of prostate cancer: an analysis of the complete treatment period of the Nutritional Prevention of Cancer Trial. BJU Int. 2003;91:608-12.

57. Karunasinghe N, Ferguson LR, Tuckey J, Masters J. Hemolysate thioredoxin reductase and glutathione peroxidase activities correlate with serum selenium in a group of New Zealand men at high prostate cancer risk. J Nutr. 2006;136:2232-35

58. Romanowska M, Kikawa KD, Fields JR, Maciag A, North SL, Shioa YH, et al. Effects of selenium supplementation on expression of glutathione peroxidase isoforms in cultured human lung adenocarcinoma cell lines. Lung Cancer. 2007;55:35-42

59. Kocdor H, Cehreli R, Kocdor MA, Sis B, Yilmaz O, Canda T et al. Toxicity induced by the chemical carcinogen 7,12-dimethylbenz[a]anthracene and the protective effects of selenium in Wistar rats. J Toxicol Environ Health A. 2005;68:693-701.

60. Rafferty TS, Walker C, Hunter JA, Beckett GJ, McKenzie RC. Inhibition of ultraviolet $B$ radiation-induced interleukin 10 expression in murine keratinocytes by selenium compounds. Br J Dermatol.2002;146:485-9.

61. Bjorkhem-Bergman L, Torndal UB, Eken S, Nystrom C, Capitanio A, Larsen $\mathrm{EH}$, et al. Selenium prevents tumor development in a rat model for chemical carcinogenesis. Carcinogenesis. 2005;26:125-31.

62. Bardia A, Tleyjeh IM, Cerhan JR, Sood AK, Limburg PJ, Erwin PJ, et al. Efficacy of antioxidant supplementation in reducing primary cancer incidence and mortality: systematic review and meta-analysis. Mayo Clin Proc. 2008;83:23-34.

63. Peters $U$, Takata Y. Selenium and the prevention of prostate and colorectal cancer. Mol Nutr Food Res. 2008;52:1261-72.

64. Nadiminty N, Gao AC. Mechanisms of selenium chemoprevention and therapy in prostate cancer. Mol Nutr Food Res. 2008;52:1247-60.

65. Rudolf E, Králová V, Cervinka M. Selenium and colon cancer--from chemoprevention to new treatment modality. Anticancer Agents Med Chem. 2008;8:598-602.

66. Reid ME, Duffield-Lillico AJ, Sunga A, Fakih M, Alberts DS, Marshall JR. Selenium supplementation and colorectal adenomas: an analysis of the nutritional prevention of cancer trial. Int J Cancer. 2006;118:1777-81.

67. Etminan M, FitzGerald JM, Gleave M, Chambers K. Intake of selenium in the prevention of prostate cancer: a systematic review and meta-analysis. Cancer Causes Control. 2005;16:1125-31

68. Meuillet E, Stratton S, Cherukuri DP, Goulet AC, Kagey J, Porterfield B, et al. Chemoprevention of prostate cancer with selenium: an update on current clinical trials and preclinical findings. J Cell Biochem. 2004;91:443-58.

69. Al-Taie OH, Seufert J, Karvar S, Adolph C, Mörk H, Scheurlen M, et al. Selenium supplementation enhances low selelnium levels and stimulates glutathione peroxidase activity in peripheral blood and distal colon mucosa in past and present carriers of colon adenomas. Nutr Cancer. 2003;46:125-30.

70. Brinkman M, Buntinx F, Muls E, Zeegers MP. Use of selenium in chemoprevention of bladder cancer. Lancet Oncol. 2006;7:766-74.

71. Sieja K, Talerczyk M. Selenium as an element in the treatment of ovarian cancer in woman receiving chemotherapy. Gynecol Oncol. 2004;93:320-7.

Artigo recebido: 8/10/09

Aceito para publicação: 12/4/10 